\title{
PLAYAS DE ACRECIÓN: CRONOLOGÍA Y PROCESOS DE FORMACIÓN DEL REGISTRO ARQUEOLÓGICO EN LA COSTA CENTRAL DE LA BAHÍA SAN SEBASTIÁN, TIERRA DEL FUEGO (ARGENTINA)
}

\author{
CRISTIAN M. FAVIER DUBOIS ${ }^{1}$ Y LUIS A. BORRERO ${ }^{2}$
}

\begin{abstract}
RESUMEN
En este trabajo se analizan, desde un enfoque geoarqueológico, la cronología y los procesos de formación de la evidencia arqueológica recuperada en superficie en la costa central de la bahía San Sebastián. Para ello se han tenido en cuenta los trabajos geológicos previos referidos a la evolución geomorfológica de esta bahía, que incluyen numerosas dataciones radiocarbónicas, a los que se incorporaron expectativas arqueológicas acerca del uso humano de esos espacios y el análisis preliminar de la evidencia recuperada. Esta porción de la faja costera comienza a progradar a partir del Holoceno medio, dando origen con el tiempo a una extensa planicie supramareal en la que se desarrollan sucesivos cordones de tormenta o cheniers, con dirección general N-S. Los fechados radiocarbónicos obtenidos en estos cordones permiten asignar cronología a las superficies paulatinamente disponibles para la ocupación humana, proveyendo edades máximas a los materiales arqueológicos recuperados entre las alineaciones. De esta manera, y en conjunto con el análisis de los procesos de formación del registro arqueológico, se hace posible contextualizar los materiales recuperados a partir de los estudios distribucionales implementados en el área, así como orientar las estrategias de investigación futura.
\end{abstract}

PALABRAS CLAVES: Tierra del Fuego, geoarqueología, cheniers, cronología.

\section{PROGRADATION OF BEACHES: CHRONOLOGY AND FORMATION PROCESSES OF THE ARCHAEOLOGICAL RECORD IN THE CENTRAL COASTLINE OF SAN SEBASTIAN BAY, TIERRA DEL FUEGO (ARGENTINA)}

\footnotetext{
ABSTRACT

This paper presents a geoarchaeological analysis of the chronology and formation processes associated with the accumulation of the archaeological record at San Sebastian Bay. Both expectations about the past human use of the area and the analysis of recovered archaeological material are contextualized in relation to previous research about the geomorphic evolution of the bay. The onset of progradation at these beaches, during the middle Holocene, led to the formation of extended supratidal flats, with aligned North-South chenier ridges. By providing maximum

1 CONICET-INCUAPA Departamento de Arqueología, Facultad de Ciencias Sociales (UNCPBA) Av. del Valle 5737 (7400) Olavarría, Argentina. E-mail: cfavier@coopenet.com.ar

2 CONICET-IMHICIHU Departamento de Investigaciones Prehistóricas y Arqueológicas, Saavedra 15 (1083) Ciudad de Buenos Aires, Argentina. E-mail: dipa.imhicihu@conicet.gov.ar
} 
ages for the archaeological material from small ephemeral ponds between these ridges, the radiometric ages of the cheniers allow us to formulate a chronology for the appearance of surfaces amenable to human occupation. This chronological framework, together with study of the formation processes of the archaeological record, contextualize the archaeological material found in this region and orients future research strategies.

KEY WORDS: Tierra del Fuego, geoarchaeology, chenier ridges, chronology.

\section{INTRODUCCIÓN}

En este trabajo se busca integrar la información geológica y arqueológica disponible para la costa central de la bahía San Sebastián, sector de llanura de cheniers, en un enfoque geoarqueológico que sea de utilidad para el análisis de la ocupación humana del área y de los procesos de formación del registro a escala amplia. Una perspectiva como ésta puede aplicarse en múltiples escalas. Aquí desarrollaremos algunos resultados en una escala mesorregional (Dincauze 2000) tendiente a valorar el registro arqueológico de superficie.

Muchas veces la arqueología de superficie ha sido criticada por su poca capacidad para generar estimaciones cronológicas. Este cuestionamiento ha sido respondido de diferentes maneras, una de ellas fue a través de una cronología de los depósitos sobre los que se acumuló el material cultural. Esta cronología, además de ofrecer resultados novedosos en términos de la comprensión del teatro de operaciones humanas en el pasado, funciona como la primera etapa para el desarrollo de proyectos que utilizan evidencia de superficie. Tal estudio busca generar indicadores temporales de la génesis de dichos depósitos, o sea de los sustratos sobre los que ocurrieron las ocupaciones humanas. La fecha de estos depósitos otorga edades máximas posibles para el registro arqueológico que apoya sobre los mismos. Para ese fin también se pueden usar las cronologías culturales existentes, lo que en suma permite entender el tiempo de acumulación potencial de materiales. El desarrollo de esta tarea se combinó con el planteo de algunas transectas y sondeos, y los resultados, en conjunto, permiten diseñar los futuros pasos de la investigación en el área.

La historia de las ocupaciones humanas en la región comienza con el alero Tres Arroyos 1, un sitio ubicado en el Cerro de los Onas, al sur del istmo bahía Inútil-bahía San Sebastián, con presencia humana c. 10.500-10.200 AP (Massone et al. 1998; Massone 2004). Es un sector del espacio que, localizado por sobre una cota de $50 \mathrm{~m}$, estaba disponible para ser utilizado desde antes de la llegada de poblaciones humanas. Así lo prueban las dataciones de conjuntos paleontológicos en el Alero 1 , y en su talud, de c. 12.540 y 12.280 años AP respectivamente (Borrero 2003). Para el Holoceno temprano sólo se registra el caso del sitio Marazzi, en la costa de bahía Inútil, con un fechado de c. 9.000 AP (Laming Emperaire et al. 1972) que no pudo ser verificado por trabajos posteriores en el sitio (Morello et al. 1999).

\section{BAHÍA SAN SEBASTIÁN}

La bahía San Sebastián tiene forma subcircular y es de grandes dimensiones: unos $55 \mathrm{~km}$ en dirección N-S y 40 km E-O (Fig. 1), su rango mareal oscila entre 3,2 y $10,5 \mathrm{~m}$, y está bordeada por afloramientos de sedimentitas del terciario y depósitos morrénicos cuaternarios que afloran en los acantilados del norte y del sur de la misma (Codignotto y Malumián 1981; Vilas et al. 1987a; Meglioli 1994). La depresión que une a bahía Inútil (Chile) y bahía San Sebastián (Argentina) es el remanente de una artesa glacial pleistocena (Raedeke 1978). Antes de 7.000 años AP el mar inundó este valle, y durante la posterior regresión, los depósitos glacigénicos y los resultantes del retroceso del acantilado terciario fueron retrabajados en una secuencia de bancos submareales y depósitos mareales fangosos (Vilas et al. 1987a).

Una curva regional de los cambios del nivel del mar para Tierra del Fuego y el estrecho de Magallanes indica un descenso de 3,5 m desde el año 5.500 AP (Porter et al. 1984). Si a esto se suma el ascenso relativo de la región (Codignotto et al. 1992) y la continua captación de sedimentos por la bahía, puede explicarse la paulatina y constante acreción de sus playas desde entonces. Existen valores de progradación que han sido estimados en $1 \mathrm{~m} /$ año 
(Codignotto 1983; Vilas et al. 1987a), y entre 2,35 y $0,61 \mathrm{~m} / \mathrm{año}$ de acuerdo al período considerado (Ferrero 1996; Ferrero et al. 1990).

El sector es de clima frío (media anual de $+5^{\circ}$ C) y semiárido, con una precipitación media anual que ronda los $300 \mathrm{~mm}$ y con predominio de los fuertes vientos del cuadrante oeste. Fitogeográficamente corresponde a la estepa patagónica, con predominio de estepa graminosa compuesta por coirón (Festuca gracillima), mata negra (Chiliotrichum diffusum), mata verde (Lepidophyllum cupressiforme) y calafate enano (Berberis buxifolia) (Pisano 1977). En la planicie supra e intermareal de la bahía abunda la halófita Salicornia, mientras que en las turberas la vegetación más común corresponde a Sphagnum.

La bahía se ha caracterizado por ser proveedora de recursos variados que fueron aprovechados recurrentemente por los antiguos pobladores del norte de la isla. Nos referimos a la abundancia de peces y moluscos (mejillones, lapas), especialmente en el sur de la misma; a la presencia de pinnípedos (existió una lobería en la punta de la espiga El Páramo, Carrara 1952), y a sus condiciones favorables para el varamiento de grandes cetáceos (Goodall 1989). Estos recursos se complementaban con el consumo de guanacos, aves y probablemente roedores, de acuerdo con las evidencias del registro arqueológico (Borrero 1979; Borrero y Casiraghi 1980; Horwitz 1995).

\section{MARCO GEOLÓGICO Y GEOMORFOLÓGICO}

Aflora en la bahía San Sebastián una secuencia terciaria marina que se presenta en forma de reducidos y discontinuos afloramientos que asoman bajo la extensa cubierta cuaternaria de la región (Codignotto y Malumián 1981). Estos afloramientos conforman cerros bajos y amesetados como es el caso del Cerro de los Gatos y del Cerro Las Bandurrias, de no más de unos $20 \mathrm{~m}$ sobre el nivel del mar. La cubierta cuaternaria está representada fundamentalmente por depósitos de origen glaciario denominados Drift Tapera Sur por Codignotto (1979), o Drifts Pampa de Beta, Río Cullen, y Sierras de San Sebastián por Meglioli (1994) quien hace corresponder estos depósitos a tres de las seis glaciaciones que determina para Tierra del Fuego y el extremo sur de Patagonia.
Con posterioridad a la última glaciación, se inició una tendencia marina transgresiva que desde el Pleistoceno tardío continuó durante parte del Holoceno, hasta hace unos 7.000 años AP (transgresión Flandriana). En aquellos momentos se inició una fase regresiva que se mantuvo activa hasta el presente (Codignotto 1996; Vilas et al. 1999). En relación con la dinámica actual Vilas et al. (1987a y 1999) diferencian 6 subáreas de sedimentación a lo largo de la costa de la bahía, que en sentido norte-sur, consisten en (Fig. 1):

A) Península del Páramo; B) Llanura mareal fangosa; C) Llanura de cheniers; D) Playas con llanuras mareales fangosas y arenosas; E) Costa acantilada; F) Complejo playa barrera-lagoon.

Los estudios a los que hace referencia este trabajo se ubican principalmente en la subárea $C$ o llanura de cheniers (Tabla 1). Las investigaciones realizadas han involucrado el diseño de transectas para la recolección de información arqueológica, la excavación de loci de particular interés (Borrero

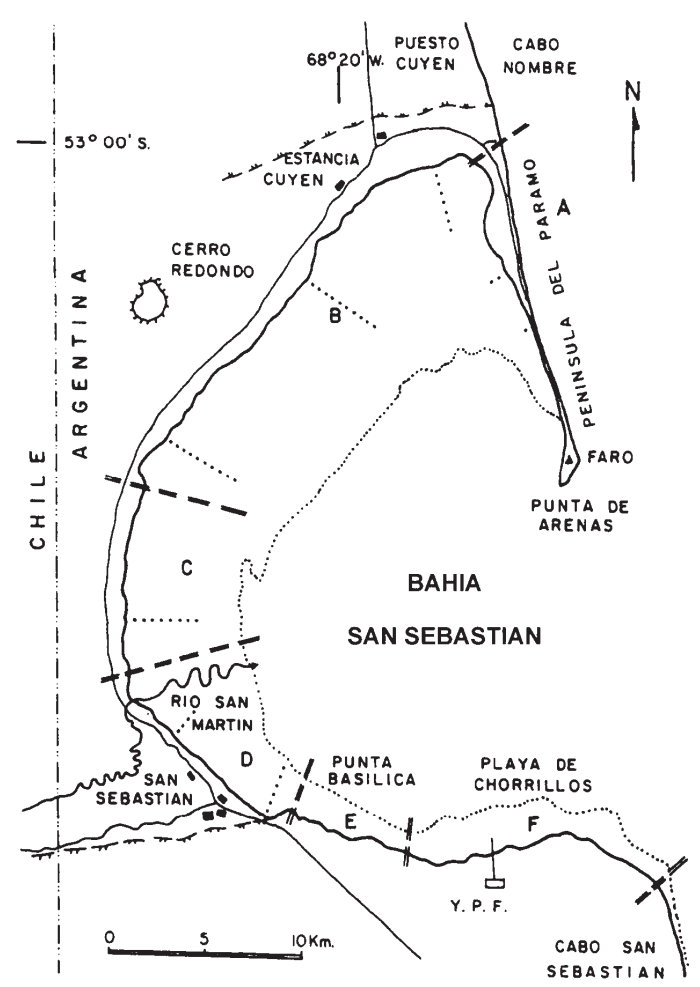

Fig. 1. Bahía San Sebastián. Incluye las subáreas de sedimentación propuestas por Vilas et al. 1999 (mapa tomado de este trabajo). 
Tabla 1. Clasificación esquemática de las unidades y subunidades reconocidas en la subárea de llanura de cheniers, y su dinámica geomorfológica.

\begin{tabular}{|l|l|l|}
\hline \multicolumn{1}{|c|}{$\begin{array}{c}\text { Unidades principales } \\
\text { reconocidas }\end{array}$} & \multicolumn{1}{c|}{ Subunidades } & \multicolumn{1}{c|}{ Dinámica geomorfológica } \\
\hline Planicie mareal actual & -- & Sedimentación activa. \\
\hline \multirow{4}{*}{ Planicie supramareal } & Cheniers y planicie ppd. & Depósitos estabilizados por vegetación. \\
\cline { 2 - 3 } & Lagunas alineadas & $\begin{array}{l}\text { Morfodinámicamente activas. Poseen agua estacionalmente y } \\
\text { migran hacia el E, erosionando la planicie y los cheniers que } \\
\text { se desarrollan en ella. }\end{array}$ \\
\hline \multirow{4}{*}{ Afloramientos terciarios } & Mantos eólicos & Depósitos estabilizados por vegetación. \\
\cline { 2 - 3 } & Hoyadas de deflación & $\begin{array}{l}\text { Morfodinámicamente activas. A semejanza de las lagunas } \\
\text { representan focos de erosión, en este caso desarrollados sobre } \\
\text { depósitos eólicos. }\end{array}$ \\
\cline { 2 - 3 } & Talud de derrubios & $\begin{array}{l}\text { Actividad morfogenética muy baja, mantienen cobertura vegetal, } \\
\text { evolucionando muy lentamente. }\end{array}$ \\
\hline
\end{tabular}

1979), el análisis de restos humanos (Guichón et al. 2000; Martin et al. 2004), así como el desarrollo de estudios tafonómicos (Borella y Muñoz 2001; Borrero 2001; Borella 2004).

\section{Evolución morfológica de la bahía San} Sebastián, relevancia arqueológica

El proceso de acreción de la bahía permitió la aparición de un espacio paulatinamente disponible para la ocupación humana y el aprovechamiento de los diferentes recursos del área, cuyo emplazamiento acompañó la evolución del entrante costero. Se ilustran en la Fig. 2 cuatro etapas en los cambios morfológicos de la bahía a partir del Holoceno
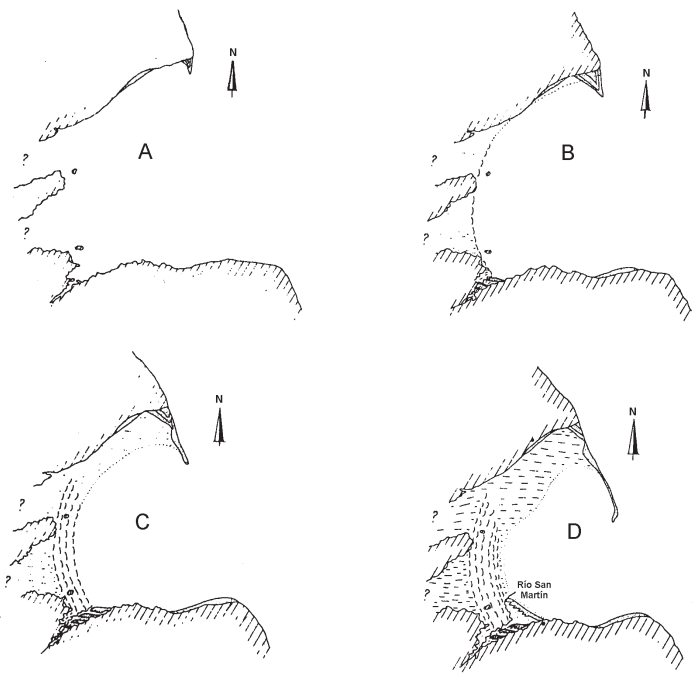

Fig. 2. Esquema evolutivo de la bahía San Sebastián (tomado de Vilas et al. 1987b). temprano/medio, según Vilas et al. (1987b). De acuerdo con estos autores se desconoce el momento exacto del comienzo de la sedimentación marina, pero por las dataciones por ellos obtenidas en depósitos regresivos (Tabla 3, muestra LF-7) sería previo a unos 5.200 años AP (Ferrero 1996; Vilas et al. 1999).

Caracterización geológica (según Vilas et al. 1987b), y arqueológica de cada etapa (Fig. 2):

(A) Hacia el sexto milenio AP, existiría una bahía mucho más extensa y de topografía más complicada con cabos, penínsulas y pequeñas islas. Los acantilados que limitaban la bahía al norte y al sur en el frente atlántico abierto, se encontraban probablemente a unos $3 \mathrm{~km}$ mar adentro de su posición actual. Se comenzó a desarrollar una paleopenínsula del Páramo.

En este contexto comienza a desarrollarse una cubierta eólica sobre los afloramientos terciarios, que contiene la evidencia más antigua recuperada en la bahía, consistente en una lente de valvas datada en c. 5.700 años AP (ver más adelante). En ese lapso, al $S$ de la actual bahía Inútil, se registran ocupaciones en el sitio Marazzi con edades de 5.570 \pm 400 años AP (Gif-1033) (Laming Emperaire et al. 1972) y de 5.440 \pm 30 años AP (Beta -125315, AMS) (Morello et al. 1999).

(B) Con posterioridad, la península crecería rápidamente hacia el sur, originándose un área protegida del oleaje atlántico al $\mathrm{O}$ de la misma, donde comenzaría a formarse la llanura intermareal fangosa. Al fondo de la bahía se iniciaría el desarrollo de cheniers durante los temporales excepcionales, mientras que en el borde sur tendría lugar la formación de complejos de playa en abanico, al abrigo de 
los cabos Cabeza de León y San Sebastián. La edad aproximada de este estadio es de 5.200 años AP, edad máxima obtenida en los cheniers más interiores (Vilas et al. 1987b). Al respecto puede mencionarse que el Prof. M. Massone recuperó restos de cetáceos en depósitos regresivos ubicados en Ea. Florentina (Chile) a unos $12 \mathrm{~km}$ de la actual costa atlántica; sobre los que se obtuvo una fecha de 4.780+80 años AP (LP- 694) (citada en Borella 1998).

(C) Hace unos 3.500-3.700 años, la Península del Páramo habría crecido protegiendo áreas cada vez más extensas de la parte norte de la bahía, donde las llanuras mareales fangosas se desarrollaban activamente. El área ocupada por los cordones de cheniers en la parte central de la bahía se reducía progresivamente por la evolución de la Península del Páramo. La playa de Chorrillos adquiriría su máxima extensión, y daría lugar a numerosas ocupaciones humanas a partir de unos 1.500 años AP (Horwitz 1995). Asimismo se registran en ese momento evidencias de ocupación en los alrededores del Cerro Cabeza de León (alero Cabeza de León, sitio BE1) (Borrero y Casiraghi 1980).

(D) En la actualidad la Península del Páramo tiene cerca de $20 \mathrm{~km}$ de longitud, y ha favorecido el establecimiento de una lobería, abandonada alrededor de los años ‘60 (Carrara 1952; Borella y Muñoz 2001, 2005). Esta espiga protege del oleaje una extensa llanura intermareal fangosa que ocupa más de la mitad norte de la bahía. Para este momento hay abundantes evidencias de ocupaciones atribuíbles a los Selknam en la zona, indicadas por la excavación de algunas improntas de probables toldos o paravientos en el Cerro de los Onas (Massone et al. 1993), y la presencia de esqueletos humanos en los sitios Laguna Mandíbulas (Guichón et al. 2000) y San Genaro (Martin et al. 2004). Es asimismo particularmente fuerte la evidencia registrada por viajeros y colonizadores (Lista 1887; Popper 1887; etc.), en algunos casos acompañada por fotos.

Este esquema evolutivo proporciona una idea de las características del paisaje en los diferentes momentos en que pudo ser utilizado por las poblaciones del pasado. Asimismo, la presencia de cheniers acota la cronología de progradación, lo que permite asignar una edad máxima a la evidencia cultural en los distintos sectores, resultando útil para evaluar el uso de aquellos espacios a lo largo del tiempo.

\section{ÁREA PARTICULAR DE ESTUDIO: LLANURA DE CHENIERS}

\section{Ubicación y características generales}

El sector en estudio se ubica inmediatamente al N del río San Martín, sur de la bahía, correspondiendo a la subárea de sedimentación C, llanura de cheniers, de Vilas et al. (1999). Su parte llana forma parte de la planicie supramareal, en la que se desarrollan antiguas líneas de costa (Codignotto y Malumián 1981) representadas por la presencia de sucesivos cordones de tormenta o cheniers (Vilas et al. 1987a; Ferrero 1996) que denominamos informalmente "cordones conchiles" por su morfología y contenido fósil. Entre estos cordones se observa la alineación de pequeños cuerpos de agua (ver Fig. 3), que durante el verano permanecen secos, manifestando abundantes artefactos líticos en superficie sobre su flanco Este.

En esta subárea se ubican también los afloramientos terciarios mesetiformes que constituyen el Cerro de los Gatos, el Cerro Las Bandurrias, y el Cerro "sin nombre". Litológicamente están conformados por areniscas líticas, correspondientes a la Formación Carmen Silva (Codignotto y Malumián 1981), constituyendo relictos en un paisaje modelado por la acción glaciaria y luego marina (Codignotto y Malumián 1981; Vilas et al. 1987a). Se hallan cubiertos por depósitos cuaternarios, principalmente Holocenos, de origen eólico, en los que se ha registrado evidencia arqueológica y tafonómica, como se verá más adelante.

\section{Morfología y cronología}

a. Unidades marinas:

Codignotto y Malumián (1981) reconocen antiguas líneas de costa de topografía rítmica en este sector. Posteriormente Vilas et al. (1987a, 1999) describen el área en términos de llanura de cheniers. Ferrero (1996) destaca la presencia de cheniers fósiles entre los que se alinean lagunas que migran hacia el $\mathrm{E}$.

De tres de las líneas de costa reconocidas por ellos, Codignotto y Malumián (1981) recuperaron material biogénico (gasterópodos) a $50 \mathrm{~cm}$ de profundidad, obteniendo fechados radiocarbónicos 


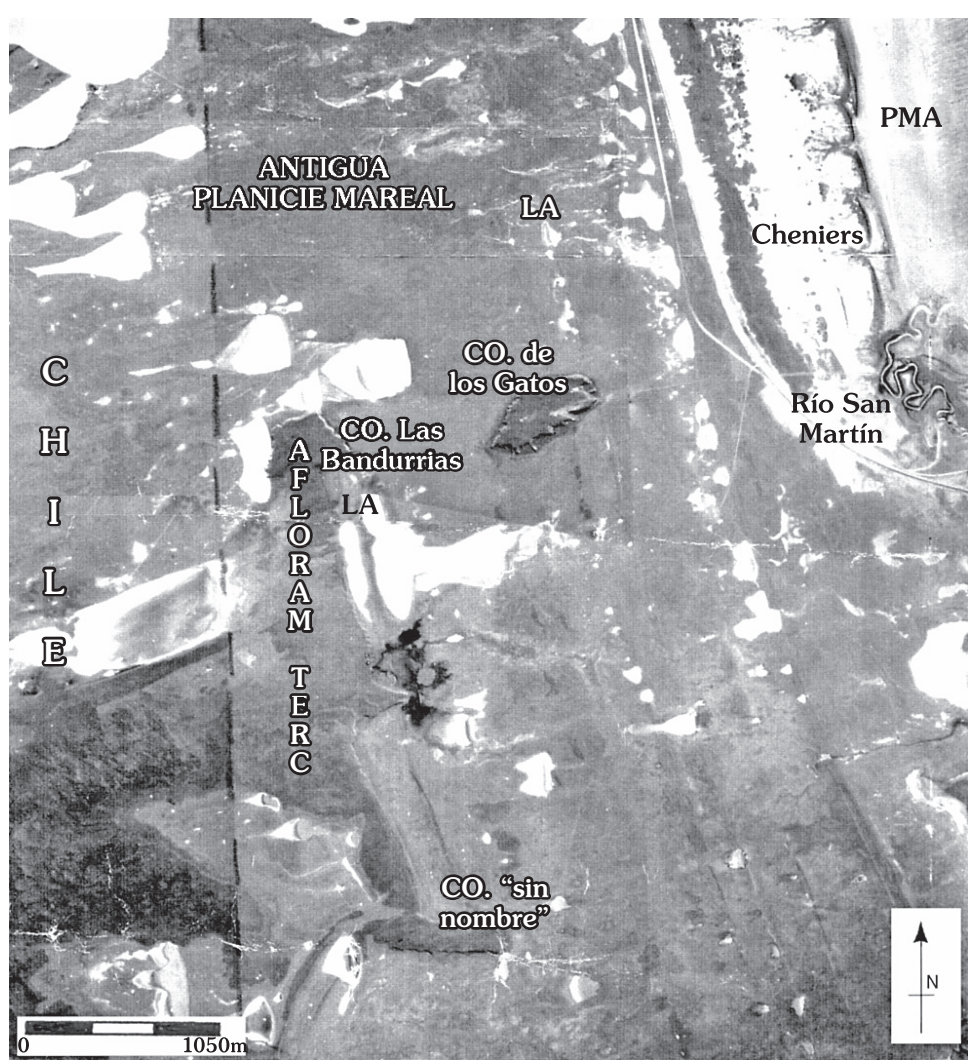

Fig. 3. Fotografía Aérea - Cerro de los Gatos y cordones conchiles (Escala 1: 35.000, año 1970, IGM). PMA: Planicie de mareas actual

LA: Lagunas alineadas en las que se fecharon los cordones conchiles que las limitan ---- transectas (Cerro de los Gatos Norte y Cerro Las Bandurrias).

a diferentes distancias de la línea de costa actual (Codignotto 1983) (Tabla 2).

Con posterioridad, Ferrero (1996) obtuvo dataciones en 12 puntos ubicados en dos líneas perpendiculares a la costa de la bahía (ver también Vilas et al. 1999). Se trata de bivalvos recuperados en las lagunas someras alineadas, que en muchos casos coinciden con cheniers fósiles (Tabla 3).

Existen semejanzas entre las edades obtenidas por ambos investigadores a distancias similares de la costa (línea de cheniers actual), a la altura del Cerro de los Gatos. El primer cordón datado por Codignotto (J01) se ubica al SO de la muestra SM-5 (ver Fig. 4), pese a ello ha resultado algo más joven. Las muestras J02/SM-7 y MP3/SM-11 pertenecen a los mismos cordones, respectivamente, habiendo proporcionado valores que estadísticamente corresponden a una misma edad [95\% de confianza] (Tabla 4).

Los 12 fechados obtenidos por Ferrero le han permitido estimar la velocidad de progradación de la costa para distintos lapsos, observándose una disminución de esta velocidad a lo largo del tiempo.

Tabla 2. Edades obtenidas por Codignotto (1983) (Ver Fig. 4).

\begin{tabular}{|l|c|c|c|}
\hline \multicolumn{1}{|c|}{ Muestra } & Distancia de la costa & Edad ${ }^{14} \mathrm{C}$ (años AP) & Rango calibrado* \\
\hline J01 & $1000 \mathrm{~m}$ & $1.310 \pm 100 \mathrm{AP}(\mathrm{AC} 23)$ & $937-728 \mathrm{AP}$ \\
\hline J02 & $2000 \mathrm{~m}$ & $2.990 \pm 80 \mathrm{AP}(\mathrm{AC} 24)$ & $2.818-2.707 \mathrm{AP}$ \\
\hline MP3 & $3500 \mathrm{~m}$ & $3.820 \pm 80 \mathrm{AP}(\mathrm{AC} 469)$ & $3.851-3.638 \mathrm{AP}$ \\
\hline
\end{tabular}

* Se agrega en este trabajo, programa CALIB 3.0 (Stuiver y Reimer 1993) 


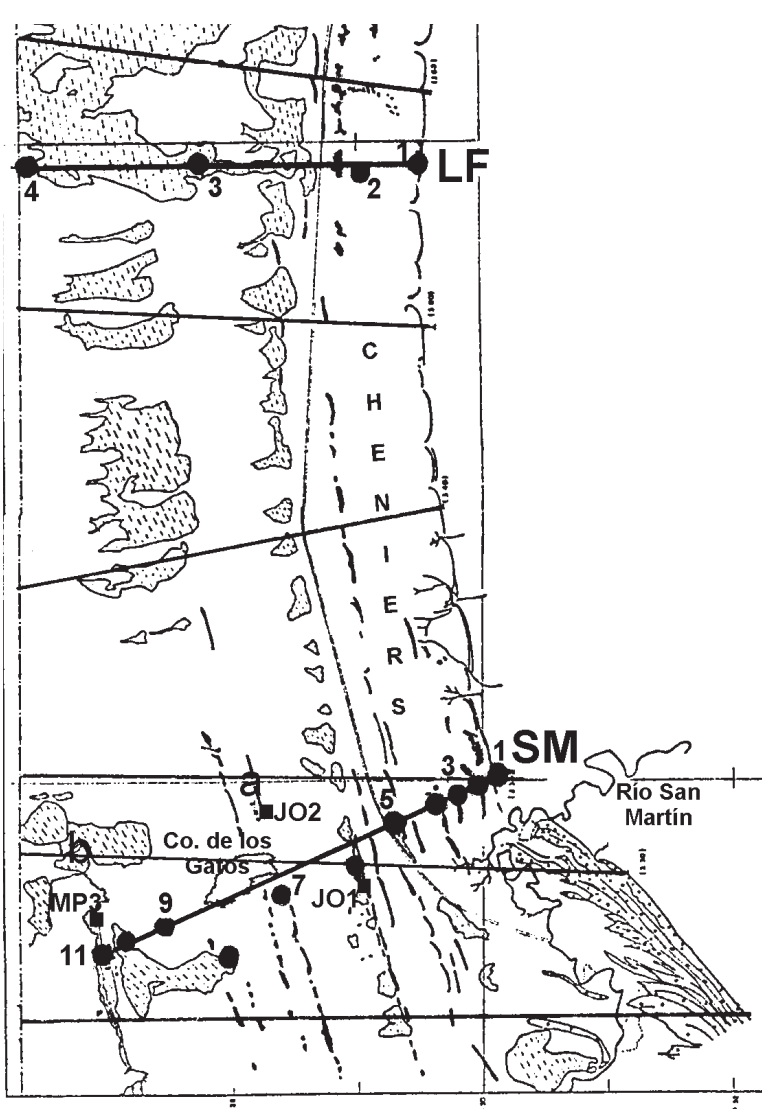

Fig. 4. Ubicación de las muestras fechadas por Codignotto (1983) y Ferrero (1996). Mapa base gentileza del Dr. M. Ferrero. b. Unidades continentales:

Respecto a los depósitos continentales, se hayan restringidos a los afloramientos terciarios del área, consistiendo en una cubierta eólica Holocena en forma de mantos, o pequeñas dunas, que no supera los 1,5 m de espesor. Asimismo, los pequeños cerros suelen presentar un talud de derrubios que apoya sobre los sedimentos supramareales que los rodean.

\section{ARQUEOLOGÍA EN LA COSTA DE ACRECIÓN (PLANICIE SUPRAMAREAL)}

Sobre la amplia planicie supramareal que domina esta subárea, el registro arqueológico ha sido relevado principalmente en superficie. Se trata en general de materiales expuestos por el efecto erosivo de lagunas estacionales al migrar hacia el $\mathrm{E}$ a causa de los fuertes vientos del cuadrante opuesto.

Se han desarrollado numerosas transectas de observación y muestreo, y se ha excavado un sondeo en un sector de la planicie supramareal aledaño al Cerro "sin nombre". El relevamiento geoarqueológico se focalizó en el estudio de los depósitos bajo erosión $y$ de las superficies sobre los que se encontraban materiales arqueológicos expuestos, con especial interés en los aspectos morfocronológicos y de evolución ambiental.

La evidencia arqueológica en superficie consiste en la presencia de materiales líticos sobre las someras lagunitas estacionales que se forman entre

Tabla 3. Dataciones radiocarbónicas obtenidas por Ferrero (1996) en sus transectas SM y LF (Fig. 4) a diferentes distancias de la costa.

\begin{tabular}{|l|c|c|c|}
\hline \multicolumn{1}{|c|}{ Muestra } & Distancia & Edad ${ }^{14} \mathrm{C}$ (años AP) & Rango calibrado* \\
\hline SM-1 & $0 \mathrm{~m}$ & $2.595 \pm 80^{1}$ & ------------ \\
\hline SM-3 & $380 \mathrm{~m}$ & $1.320 \pm 90$ & $937-748 \mathrm{AP}$ \\
\hline SM-5 & $880 \mathrm{~m}$ & $1.660 \pm 65$ & $1.270-1.146 \mathrm{AP}$ \\
\hline SM-7 & $1940 \mathrm{~m}$ & $3.195 \pm 160$ & $3.207-2.773 \mathrm{AP}$ \\
\hline SM-9 & $2960 \mathrm{~m}$ & $3.700 \pm 85$ & $3.694-3.476 \mathrm{AP}$ \\
\hline SM-11 & $3430 \mathrm{~m}$ & $4070 \pm 90$ & $4.223-3.958 \mathrm{AP}$ \\
\hline LF-1 & $0 \mathrm{~m}$ & $975 \pm 120$ & $647-480 \mathrm{AP}$ \\
\hline LF-2 & $480 \mathrm{~m}$ & $1.755 \pm 120$ & $1.395-1.181 \mathrm{AP}$ \\
\hline LF-3 & $1760 \mathrm{~m}$ & $2.970 \pm 140$ & $2.859-2.612 \mathrm{AP}$ \\
\hline LF-4 & $3300 \mathrm{~m}$ & $3.505 \pm 150$ & $3.549-3.206 \mathrm{AP}$ \\
\hline LF-5 & $4180 \mathrm{~m}$ & $4.145 \pm 90$ & $4.338-4.071 \mathrm{AP}$ \\
\hline LF-7 & $6820 \mathrm{~m}$ & $5.270 \pm 190$ & $5.858-5.442 \mathrm{AP}$ \\
\hline
\end{tabular}

${ }^{1}$ Esta datación fue desechada por Ferrero por hallarse los moluscos muy cerca de la desembocadura del río San Martín, sospechándose retransporte.

* Se agrega en este trabajo, programa CALIB 3.0 (Stuiver y Reimer 1993) 
Tabla 4. Comparación de las edades obtenidas por Codignotto (1983) y Ferrero (1996).

\begin{tabular}{|l|c|c|c|}
\hline \multicolumn{1}{|c|}{ Muestras } & Distancia de la costa & Edad ${ }^{14} \mathrm{C}$ (años AP) & Rango calibrado \\
\hline J01 & $1000 \mathrm{~m}$ & $1.310 \pm 100$ & $937-728 \mathrm{AP}$ \\
\hline SM-5 & $880 \mathrm{~m}$ & $1.660 \pm 65$ & $1.270-1.146 \mathrm{AP}$ \\
\hline J02 & $2000 \mathrm{~m}$ & $2.990 \pm 80$ & $2.818-2.707 \mathrm{AP}$ \\
SM-7 & $1940 \mathrm{~m}$ & $3.195 \pm 160$ & $3.207-2.773 \mathrm{AP}$ \\
\hline MP3 & $3500 \mathrm{~m}$ & $3.820 \pm 80$ & $3.851-3.638 \mathrm{AP}$ \\
SM-11 & $3430 \mathrm{~m}$ & $4.070 \pm 90$ & $4.223-3.958 \mathrm{AP}$ \\
\hline
\end{tabular}

los sucesivos cordones de tormenta. Los pequeños cuerpos de agua se habrían originado a causa de la deflación que actúa entre estos cordones (Ferrero 1996). Por acción del viento las lagunas migran hacia el E topándose con los cordones y generando en el contacto un perfil algo menor a un metro de desarrollo, cuya estratigrafía se esquematiza en la Fig. 5.

Durante el verano las lagunas permanecen secas observándose en la superficie materiales marinos propios del cordón conchil (moluscos, restos de peces y cetáceos), huesos de animales terrestres (guanaco, oveja), y aves, junto a material arqueológico. Se genera así una asociación aparente entre restos de diverso origen y antigüedad. Este tipo de mezcla, tan común en el registro arqueológico en general, no siempre es fácil de identificar. En este caso hemos podido acotar algunas de las condiciones que generan esos palimpsestos.

Los cuerpos lacustres relevados fueron (letras a y b en Fig. 4):

- Alineación al NNE del Cerro de los Gatos

Se realizó una transecta de unos $900 \mathrm{~m}$ de largo, desde el extremo E del Cerro de los Gatos hacia el $\mathrm{N}$, esta línea paralela a la costa pasa por cinco pequeñas lagunas (ver Fig. 3 y Tabla 5).

Se observa que en estas lagunas se han recuperado numerosos artefactos líticos, tanto instrumentos como lascas, junto a variados materiales de origen tafonómico (restos de moluscos, cetáceos, peces, aves acuáticas, guanaco, oveja), que incluyen tanto material fósil como material moderno. Se utilizó una combinación de coloración y meteorización de los huesos para distinguir los restos faunísticos modernos de los fósiles. Las especies introducidas sirvieron como control. De todas maneras no siempre fue posible realizar esta distinción con claridad. La mayoría de los hallazgos se encuentra concentrada en los extremos orientales de las lagunas secas. Su presencia allí ha de asociarse con la acción de avance de las lagunas hacia el Este. Hay que destacar que el material lítico muy raramente se encuentra en la superficie vegetada presente entre las lagunas. Lo que esta evidencia muestra, entonces, es que la erosión asociada con estas lagunas expone material lítico y faunístico, el que se mezcla con restos óseos que resultan de la "lluvia tafonómica" moderna. Esos espacios entre lagunas, entonces, tienen el potencial

Tabla 5. Materiales recuperados en la transecta Cerro de los Gatos Norte, con distancias tomadas desde este afloramiento.

Se aclara cuando se trata de fauna moderna. Si no se especifica significa que el material está en superficie.

\begin{tabular}{|c|c|c|c|}
\hline Laguna & Distancia & Evidencia faunística & Evidencia artefactual \\
\hline 1 & c. $200 \mathrm{~m}$ & $\begin{array}{l}\text { Conchilla molida, gasterópodos } \\
\text { Huesos de especies introducidas: oveja } \\
\text { Huesos modernos de ave } \\
\text { Fragmento vértebra y apófisis vertebrales de cetáceo }\end{array}$ & $\begin{array}{c}\text { Raedera } \\
\text { Lascas }\end{array}$ \\
\hline 2 & c. $300 \mathrm{~m}$ & $\begin{array}{l}\text { Conchilla molida, gasterópodos } \\
\text { Vértebra y otros huesos de cetáceo enterrados y semienterrados } \\
\text { Huesos modernos de ave }\end{array}$ & Punta de proyectil \\
\hline 3 & c. $500 \mathrm{~m}$ & $\begin{array}{l}\text { Costilla de cetáceo semienterrada } \\
\text { Cinco vértebras de cetáceos } \\
\text { Concentración de } 10 \text { vértebras de cetáceo } \\
\text { Vértebra de delfín } \\
\text { Concentración de huesos de guanaco: calcáneo, } 1^{\text {a }} \text { falange }(n=3) \text {, } \\
2^{\text {a }} \text { falange, metacarpo, metatarso, húmero, dientes, }\end{array}$ & Bola \\
\hline 4 & c. $700 \mathrm{~m}$ & $\begin{array}{l}\text { Fg. Hueso guanaco } \\
\text { Huesos de ave modernos } \\
\text { Molar de cánido }\end{array}$ & Lasca \\
\hline 5 & c. $900 \mathrm{~m}$ & Vértebras de pez & - \\
\hline
\end{tabular}


Tabla 6. Materiales recuperados en las proximidades del Cerro Las Bandurrias.

\begin{tabular}{|l|l|l|}
\hline Localización & Evidencia faunística & Evidencia lítica \\
\hline Laguna al Norte del Cerro Bandurrias & Huesos de guanaco modernos & $\begin{array}{l}\text { Desechos líticos } \\
\text { Punta de proyectil }\end{array}$ \\
\hline & $\begin{array}{l}\text { Huesos de cetáceo, probablemente removidos } \\
\text { de cordón conchil. }\end{array}$ & \\
Transectas al Norte del Cerro Bandurrias & $\begin{array}{l}\text { Huesos de guanaco, la mayoría de los cuales } \\
\text { parecen ser resultado de lluvia tafonómica. } \\
\text { Presencia de huesos de lobo (origen natural } \\
\text { o antrópico) }\end{array}$ & $\begin{array}{l}\text { Concentraciones de materiales } \\
\text { litico }\end{array}$ \\
\hline
\end{tabular}

para entregar material en estratigrafía. Sin embargo su densidad es tan baja, que se requeriría un programa de muestreo subsuperficial muy intensivo para organizar su búsqueda (McManamon 1984).

En el perfil de erosión de estos cuerpos de agua someros (perfil E) aflora el cordón conchil, muchas veces incluye restos de cetáceos, y en algún caso restos de peces. El material arqueológico debió depositarse luego de la formación del cordón conchil. De manera que en estos casos que se presentan en las cicatrices de erosión creadas por las lagunas tenemos palimpsestos formados por al menos tres conjuntos de materiales promediados, los contemporáneos a la formación del cordón, los posteriores, que tienen el potencial de incluir evidencia arqueológica asociada con restos faunísticos, y la "lluvia tafonómica" que siguió a estas ocupaciones.

- Laguna en el flanco N del Cerro Las Bandurrias, y transecta de muestreo (ver Fig. 3 y Tabla $6)$.

Se observaron aquí numerosos huesos en superficie de guanaco, aves, cetáceos y ovejas, restos abundantes de gasterópodos, y artefactos líticos en basalto. Los sondeos a pala en el perfil de erosión de la laguna no evidenciaron el cordón conchil de donde deben provenir los restos de moluscos y cetáceos, quizás haya sido totalmente erodado por la laguna, y su contenido disperso. De manera que este caso se presenta como una variante con respecto al del Cerro de los Gatos, en la que se promedian los mismos tipos de materiales, pero es mucho menos clara la evidencia de campo para dilucidar su procedencia. En este caso, sólo aplicando el conocimiento mesorregional de las sucesivas líneas de cordones conchiles, con su cronología diferencial, resulta posible considerar las fuentes alternativas de materiales. Por otra parte, en términos cronológicos, el tiempo de acumulación de material arqueológico es algo mayor al registrado en el caso de Cerro de los Gatos.
Sondeo en la planicie supramareal

Este sondeo se efectuó a raíz de la presencia de artefactos líticos y restos óseos de origen cultural, descubiertos al excavarse un canal artificial en la planicie supramareal próxima al Cerro "sin nombre". Los huesos de guanacos enterrados en estos sedimentos limosos se presentaban algo mineralizados. En las inmediaciones se encontró una punta de proyectil lítica.

Se planteó una cuadrícula arqueológica de 50×50 cm en las márgenes del canal y se profundizó hasta llegar a los $35 \mathrm{~cm}$. La superficie se hallaba cubierta de vegetación herbácea. Se recuperaron en estratigrafía escasos artefactos líticos y numerosos restos óseos de guanaco, algunos presentaban huellas de procesamiento y fractura intencional.

El límite inferior del suelo (a $32 \mathrm{~cm}$ de profundidad) constituye un contacto litológico que separa dos eventos depositacionales: el superior, eólico, luego edafizado y finalmente cubierto por turba; y el inferior de origen marino (sedimentos mareales) que presenta en planta grietas de desecación poligonales.

La evidencia cultural se restringe al depósito eólico limoarcilloso superior, y desaparece en el contacto con los sedimentos correspondientes a la planicie supramareal. Este sondeo se ubica a pocos metros del Cerro "sin nombre", afloramiento del que provienen los clastos tamaño gravilla de arenisca presentes en el nivel 8-32 cm.

\section{La evidencia sobre los afloramientos terciarios}

Se han relevado los siguientes cerros que asoman en la planicie de acreción marina: de los Gatos, Las Bandurrias y "sin nombre" (ver Fig. 3). Estos afloramientos de areniscas desarrollan oquedades (tafoni), y conforman pequeños reparos en 
forma de aleritos en el contacto con los sedimentos marinos. Presentan concreciones ferruginosas que han sido muestreadas por su potencial como material pigmentante (Nora Franco, com. pers.). En los sedimentos eólicos que se desarrollan sobre ellos se observa con frecuencia la presencia de un suelo enterrado.

El relevamiento arqueológico consistió en el desarrollo de transectas de muestreo, y la excavación de sondeos. Estos se realizaron en los depósitos eólicos de los cerros Las Bandurrias y de los Gatos, y en talud de derrubios del Cerro "sin nombre".

\section{Cerro de los Gatos}

Este cerro, de forma ovalada en planta y de unos $500 \mathrm{~m}$ de diámetro máximo, se eleva sobre la antigua planicie mareal de la bahía en las proximidades de la desembocadura del río San Martín (Fig. 3).

Su sector oriental presenta una hoyada de deflación, ubicada a unos $2 \mathrm{~km}$ de la costa actual, en la que se observaron numerosas valvas de gasterópodos en estratigrafía, y sobre la superficie. Las de estratigrafía se ubicaban por debajo de un suelo enterrado (ver perfil tipo en Fig. 6), del que se tomaron muestras de los horizontes $2 \mathrm{~A}$ y $2 \mathrm{AC}$ para su datación por OCR.

En este lugar se realizó un sondeo a fin de procurar alguna información útil para determinar el origen de la acumulación de moluscos. La distribución de los gasterópodos (Odonthocymbiola $s p$.) se restringe a un sector con pendiente hacia el mar, en el flanco E del cerro, próximo a un cordón de tormenta sobre la antigua planicie mareal. Los ejemplares poseen distintos tamaños, completos y fragmentados, y se presentan dispersos. Su excavación no proveyó ningún material cultural; han sido datados por ${ }^{14} \mathrm{C}$ en $900 \pm 115$ años AP (AC1483).

Cabe preguntarse cómo llegaron estos moluscos allí. El cordón conchil que pasa inmediatamente al este de este locus (2000 m de la costa) fue datado en unos 3.000 años AP (muestras J02 y SM-7), por lo que el mar no se hallaría cerca de este sector al depositarse los gasterópodos en la matriz eólica arenosa. Su presencia podría vincularse con actividades de origen cultural, pero no debe descartarse el transporte por algún animal (en particular aves). No es claro el patrón en ningún caso por lo que la cuestión permanece abierta.

\section{Cerro Las Bandurrias}

Este cerro se encuentra al $\mathrm{O}$ del Cerro de los Gatos (Fig. 3) y posee unos 300 m de extensión máxima. Sobre su flanco oriental, ubicado a unos $3,5 \mathrm{~km}$ de la costa actual, se registró una lente de valvas de mejillones (Mytilus sp.), que afloraba hacia la base de la cubierta eólica Holocena. La lente presentaba una dispersión de valvas a lo largo de $2 \mathrm{~m}$, con un espesor máximo de $15 \mathrm{~cm}$. En algunos otros sectores deflacionados de este cerro, se hallaron en superficie instrumentos líticos, aunque escasos.

La excavación de la lente no proporcionó ningún material de evidente origen cultural, pero a diferencia de lo que ocurre con los gasterópodos del Cerro de los Gatos, las valvas de Mytilus que conforman esta acumulación están ausentes o son muy excepcionales en los depósitos de tormenta supramareales (cordones conchiles) que rodean al cerro. La geometría del depósito, su localización y la presencia de una única especie sugieren un origen cultural para esta lente de valvas. La datación de las mismas arrojó una edad de 5.700 \pm 180 años AP (AC 1599). Esta fecha es la más antigua obtenida en toda el área para un depósito costero de origen cultural, y calibrada involucra el rango 5.898 - 6.200 años AP.

Al sur del Cabo San Sebastián (límite sur de la bahía), en el sitio Laguna Arcillosa 1, Salemme y Bujalesky (2001) obtuvieron una edad sobre Mytilus sp. de 5.410 \pm 70 años AP (CSIR-7685) en un depósito eólico equivalente al que se desarrolla en el Cerro Las Bandurrias, aunque ubicado en este caso a unos $2 \mathrm{~km}$ de la costa actual, en una geografía algo distinta. Estas edades constituyen la cronología más antigua para los sitios costeros del área.

\section{Cerro "sin nombre"}

Este afloramiento se ubica al sur de los anteriores (Fig. 3), a unos 4000 m de la costa actual, y posee un largo máximo de unos $500 \mathrm{~m}$. Ya se ha informado del sondeo realizado en la planicie supramareal próxima a este cerro. Se ha realizado asimismo un sondeo arqueológico de $50 \times 50 \mathrm{~cm}$ en el talud de derrubios de su flanco NE. El mismo se profundizó hasta los $80 \mathrm{~cm}$ de la superficie, recuperándose artefactos líticos, y numerosos restos 
óseos de guanaco, roedores y oveja. La estratigrafía revela que este depósito se encuentra edafizado en su parte superior. Una pelvis-sacro de guanaco con huellas culturales, obtenida entre 70 y $75 \mathrm{~cm}$ de profundidad, fue datada en $1.250 \pm 60$ años AP (Beta-116975).

Destacamos en este caso la presencia de huesos de guanaco -algunos mineralizados- que por su posición y características reclaman un origen un poco anterior al de la actual "lluvia tafonómica". Resulta difícil decidir, en muchos de estos casos, el origen de los huesos. La situación contextual, o la presencia de huellas de corte, como en los restos fechados, resulta la única guía segura.

Estratigrafía general de los depósitos cuaternarios de los cerros

Los depósitos eólicos que se desarrollan sobre los afloramientos terciarios presentan hacia el tope de la secuencia un suelo de moderado desarrollo (horizontes A-AC-C). Éste se halla sepultado en muchas ocasiones y es morfológicamente similar al observado en secuencias eólicas y coluviales de otras localidades de la bahía. La cubierta eólica (esquematizada en la Fig. 6) se corresponde granulométrica y mineralógicamente con la de los mantos y dunas desarrollados sobre el cercano Cerro Cabeza de León (CIRGEO 1996), ya que el área de procedencia de los materiales clásticos la constituyen los afloramientos de la Fm. Carmen Silva ubicados hacia el oeste.

Hacia la base de estos depósitos se observan guijarros de origen glacifluvial, apoyados sobre las areniscas terciarias que conforman estos cerros. Tales guijarros constituyen el único registro de edad Pleistocena sobre estas sedimentitas, se observan dispersos y carentes de toda matriz, probablemente por haber sufrido retrabajo marino en momentos transgresivos.
En estos depósitos ha sido frecuente observar restos óseos de guanaco tafonómicos, y en los sectores deflacionados, escasos materiales líticos en superficie; pero no se han registrado aún artefactos incluidos en los perfiles arenosos, considerados su matriz de procedencia. En cuanto al origen de estos restos, destaquemos que hay registro de depositación de restos de guanaco en las cumbres de los cerros. En estos casos, dependiendo de la topografía, se dan limitadas condiciones de enterramiento. La mayoría de esos restos, sin embargo, de permanecer en superficie se meteorizan completamente en lapsos del orden de las dos décadas. Por lo tanto las asociaciones físicas entre esos huesos de guanaco y restos líticos en superficie no son duraderas. Los huesos enterrados se recuperan generalmente enteros, presentando variado grado de meteorización, y con señales de estabilidad (medida por su exposición diferencial a los elementos). Estas dos últimas propiedades implican exposiciones del orden de un lustro antes de enterrarse.

\section{CRONOLOGÍA}

\section{Planicie supramareal}

La cronología de los materiales arqueológicos recuperados en superficie, y en el sondeo arqueológico efectuado, se estima en forma indirecta de acuerdo a la edad de los cheniers inactivos que se ubican en los sectores relevados (Tabla 7). Estas constituyen edades máximas para el registro de actividades humanas, cuya presencia se supone posterior a los depósitos marinos.

\section{Depósitos sobre los afloramientos terciarios}

Se trata de edades obtenidas en la cubierta eólica que se desarrolla sobre los cerros, que se halla edafizada hacia el tope de la secuencia (Tabla 8).

Tabla 7. Edades máximas para la evidencia arqueológica relevada.

\begin{tabular}{|c|c|c|}
\hline Sector relevado & Distancia de la costa & $\begin{array}{l}\text { Cronología máxima: edades }{ }^{14} \mathrm{C} \text { en los } \\
\text { cheniers más próximos (ver Tabla 2) }\end{array}$ \\
\hline Alineación de lagunas al NE del Cerro de los Gatos & $2000 \mathrm{~m}$ & $\begin{array}{c}2.990 \pm 80 \text { AP (J02) y } 3.195 \pm 160 \text { AP } \\
(\mathrm{SM}-7)\end{array}$ \\
\hline Laguna en el flanco N del Cerro Las Bandurrias & Ca. $3500 \mathrm{~m}$ & $\begin{array}{c}3.820 \pm 80 \text { AP }(\mathrm{MP} 3) \text { y } 4.070 \pm 90 \mathrm{AP} \\
(\mathrm{SM}-11)\end{array}$ \\
\hline Sondeo cercano al Cerro "sin nombre" & Ca. $3500 \mathrm{~m}$ & $\begin{array}{c}3.820 \pm 80 \mathrm{AP}(\mathrm{MP} 3) \text { y } 4.070 \pm 90 \mathrm{AP} \\
(\mathrm{SM}-11)\end{array}$ \\
\hline
\end{tabular}


Tabla 8. Edades ${ }^{14} \mathrm{C}$ obtenidas en los cerros.

\begin{tabular}{|l|c|c|c|c|}
\hline \multicolumn{1}{|c|}{ Sector } & Material & Posición estratigráfica & Edad ${ }^{14}$ C (años AP) & Rango calibrado \\
\hline $\begin{array}{l}\text { Cerro de los } \\
\text { Gatos }\end{array}$ & Gasterópodos & Horizontes 2A y 2AC & $900 \pm 115$ (AC1483) & $432-578 \mathrm{AP}$ \\
\hline $\begin{array}{l}\text { Cerro Las } \\
\text { Bandurrias }\end{array}$ & Lente de mejillones & Base del horizonte C & $5.700 \pm 180$ (AC 1599) & $6.284-5.898 \mathrm{AP}$ \\
\hline $\begin{array}{l}\text { Cerro "sin } \\
\text { Nombre" }\end{array}$ & Hueso de guanaco & Horizonte C & $1.250 \pm 60$ (Beta-116975) & $1.266-1.069 \mathrm{AP}$ \\
\hline
\end{tabular}

* Este valor se aproxima a unos 500 años AP, una edad que parece demasiado joven para constituir un momento previo al desarrollo del suelo enterrado que los suprayace (el horizonte 2AC fue fechado en 770 años AP por OCR, ver abajo). Sin embargo, a $2 \sigma$ la edad tiene un error de \pm 230 años, y podría incluir un efecto reservorio menor al promedio de 400 años que introduce el programa de calibración (Calib 3.0, Stuiver y Reimer 1993).

* Incluye la resta de 400 años por efecto reservorio.

Respecto al sondeo en el talud del Cerro "sin nombre", al apoyarse este pequeño talud sobre los sedimentos supramareales (su desarrollo comienza luego de retirado el mar) la cronología máxima del coluvio es la de los depósitos marinos que lo infrayacen, estimada en este sector en unos 4.000 años (punto anterior).

\section{Dataciones obtenidas por OCR}

Se trata de dataciones sobre materia orgánica de suelos efectuadas mediante el método químico denominado OCR -Oxidizable Carbon Ratio- (Frink 1995). Se procesaron muestras provenientes del suelo desarrollado sobre los depósitos eólicos, que se observa enterrado en algunas posiciones del paisaje (Tabla 9).

Si bien estas edades no han sido informadas con el error asociado, el mismo ronda el 3\% de acuerdo a las consideraciones del autor del método (Frink 1995).

\section{EVOLUCIÓN AMBIENTAL}

Síntesis esquemática de la evolución ambiental del área de acuerdo con las unidades marinas y continentales relevadas (Tablas 10 y 11).

\section{DISCUSIÓN}

\section{Procesos de formación del registro arqueológico}

La ocupación humana ocurrió sobre los distintos sustratos reconocidos, lo que otorga una edad máxima para muchos de los materiales arqueológicos allí depositados. Gran parte de las observaciones -geoarqueológicas y tafonómicas- se realizaron para tratar de entender los procesos de formación del registro arqueológico, que en este sector presenta modalidades muy diferentes, a saber:

A) La primera tiene que ver con la acción erosiva de las lagunas someras sobre los depósitos supramareales, y aquellos que los suprayacen. La

Tabla 9. Edades sobre materia orgánica en los diferentes horizontes pedológicos.

\begin{tabular}{|l|c|c|}
\hline \multicolumn{1}{|c|}{ Sector } & Horizonte datado & Edad obtenida \\
\hline $\begin{array}{l}\text { Cerro de los Gatos } \\
\text { (perfil gasterópodos) }\end{array}$ & $2 \mathrm{~A}(-35 \mathrm{~cm})$ & 168 años AP (ACT\#2034) \\
\cline { 2 - 3 } & $2 \mathrm{AC}(-65 \mathrm{~cm})$ & 772 años AP (ACT\#2802) \\
\hline
\end{tabular}

Tabla 10. Planicie supramareal.

\begin{tabular}{|c|c|c|}
\hline Cronología & Eventos geomórfico-ambientales & Fig. 5 \\
\hline \multirow{3}{*}{ Holoceno tardío-reciente } & $\begin{array}{l}\text { IV. Deflación, y efecto erosivo de las lagunas someras al } \\
\text { migrar hacia el E }\end{array}$ & \multirow{4}{*}{$\begin{array}{l}\text { Fig. } 5 \text { - Columna Representativa. } \\
\text { I Cerfil lustrativo de la estratigrafía de la } \\
\text { I lanicie supramareal, expuesta por erosión } \\
\text { en la margen E de las lagunas estacionales } \\
\text { desarrolladas entre los cheniers. }\end{array}$} \\
\hline & $\begin{array}{l}\text { III. Pedogénesis, acompañada en algunos sectores por } \\
\text { desarrollo de turba }\end{array}$ & \\
\hline & II. Sedimentación eólica de grano fino & \\
\hline Holoceno medio-tardío & $\begin{array}{l}\text { I. Sedimentación supramareal. Incluye depósitos de } \\
\text { tormenta de cronología creciente hacia el O (edades } \\
\text { calibradas entre ca. } 550 \text { y } 5600 \text { años AP). }\end{array}$ & \\
\hline
\end{tabular}


Tabla 11. Cubierta cuaternaria de los afloramientos terciarios.

\begin{tabular}{|c|c|c|}
\hline Cronología & Eventos geomórfico-ambientales & Fig. 6 \\
\hline \multirow{3}{*}{$\begin{array}{l}\text { Holoceno tardío- } \\
\text { reciente }\end{array}$} & $\begin{array}{l}\text { V. Pedogénesis incipiente (entisol) sobre el último } \\
\text { depósito }\end{array}$ & \multirow{6}{*}{ 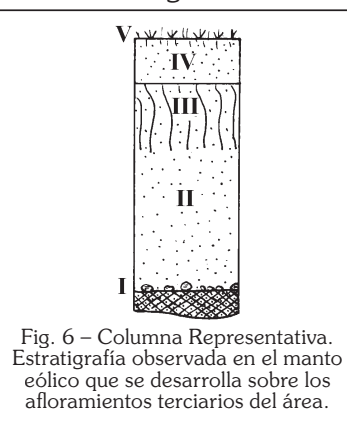 } \\
\hline & $\begin{array}{l}\text { IV. Reactivación de la sedimentación eólica, se sepulta el } \\
\text { suelo. Edad máxima de este evento ca. } 170 \text { años AP. }\end{array}$ & \\
\hline & $\begin{array}{l}\text { III. Pedogénesis. Desarrollo de un suelo (molisol) con } \\
\text { horizontes A-AC-C, y una edad mínima de } 720 \text { años AP. }\end{array}$ & \\
\hline Holoceno medio-tardío & $\begin{array}{l}\text { II. Sedimentación eólica a partir de ca. } 6000 \text { cal. AP (edad } \\
\text { de la lente de Mytilus). }\end{array}$ & \\
\hline $\begin{array}{l}\text { Holoceno temprano a } \\
\text { medio }\end{array}$ & $\begin{array}{l}\text { I. Manto de gravas de textura calada por retrabajo marino } \\
\text { de las gravas glaciarias (pérdida de matriz original) }\end{array}$ & \\
\hline Pleistoceno & $\begin{array}{l}\text { Depositación de diamictos glaciarios (till) y sedimentos } \\
\text { glacifluviales. }\end{array}$ & \\
\hline
\end{tabular}

presencia de moluscos, huesos de cetáceos y otros restos característicos del cordón conchil, redepositados sobre el fondo de las lagunas, respondería únicamente a la acción erosiva que realizan estos cuerpos de agua. El material lítico que se observa en la misma superficie, podría provenir del depósito eólico superior de grano fino (en el sondeo próximo al Cerro "sin nombre" se halló material lítico en capa en estos sedimentos), o, eventualmente, de la capa de turba que en muchas ocasiones lo suprayace. El pequeño tamaño de las lagunas y su carácter estacional sugieren que su desarrollo es relativamente reciente, no pudiendo haber sido sus márgenes receptoras primarias de los vestigios arqueológicos. La erosión de perfiles por parte de los pequeños cuerpos de agua es lo que generó una asociación aparente entre ellos.

Estos palimpsestos que encontramos en superficie, reflejan procesos similares a los observados en las lagunas del norte de la bahía (lagunas Las Mandíbulas). Allí el hallazgo de un esqueleto humano en un sector aún no erosionado por el agua (laguna Las Mandíbulas 1) (Guichón et al. 2000) con un fechado moderno, confirma que la vinculación en superficie de artefactos líticos y restos marinos es resultado del contexto secundario en el que se encuentran ambos registros a causa de procesos dinámicos.

B) La segunda modalidad se halla vinculada con los depósitos eólicos arenosos que se desarrollan sobre los afloramientos terciarios. En este caso los materiales arqueológicos (i.e. lente de Mytilus del Cerro Las Bandurrias) están incluidos en secuencias con tasas de sedimentación moderadas a elevadas (mantos eólicos) que han permitido una preservación adecuada de los materiales de origen orgánico (valvas, restos óseos). Este es el mismo contexto estratigráfico en el que se han hallado materiales arqueológicos al sur del Cabo San Sebastián, en los sitios Chacra Pafoy, Lagunas Arcillosa 1 y 2, y El Pedrero (Salemme y Bujalesky 2001).

C) La tercera modalidad en los procesos de formación del registro arqueológico corresponde a la dinámica del talud que se desarrolla en el contacto de los afloramientos terciarios con los sedimentos marinos. En este caso la sedimentación deriva de la lenta meteorización/erosión de los pequeños aleros desarrollados a expensas de las areniscas, y del esporádico aporte eólico. Las tasas de sedimentación resultan predominantemente bajas, pero han posibilitado la preservación del registro óseo en estratigrafía (i.e. talud del Cerro "sin nombre"). Otros materiales arqueológicos y tafonómicos recuperados de un talud provienen de aquel desarrollado en el Cerro Cabeza de León, en el sur de la bahía (Borrero 1979), que por su magnitud ha sido objeto de trabajos específicos (Favier Dubois 1998; Martin y Borella 1999).

\section{Entorno ambiental de las ocupaciones humanas}

Se trata de un sector de costa paulatinamente abandonado por la dinámica marina. Presenta depósitos litorales bioclásticos que permiten estudios de cronologías de acreción de la bahía con mayor detalle respecto a otras áreas analizadas.

La edad de la lente antrópica localizada en el Cerro Las Bandurrias corresponde a un nivel del mar elevado durante la transgresión del Holoceno medio que, en aquel momento, rodeaba estos afloramientos rocosos. La presencia de mejillones (Mytilus sp.) en este lugar puede explicarse atendiendo a 
Tabla 12. Síntesis de la dinámica ambiental/cultural en las distintas unidades del sector estudiado a partir del Holoceno medio.

\begin{tabular}{|c|c|c|}
\hline SECTOR & ca. 6.000-1.000 AP & ca. 1.000 AP - presente \\
\hline $\begin{array}{l}\text { ANTIGUA } \\
\text { PLANICIE } \\
\text { MAREAL }\end{array}$ & $\begin{array}{l}\text { Regresión marina evidenciada por sucesivos } \\
\text { cordones de tormenta. } \\
\text { Evidencia cultural vinculada con márgenes de lagunas } \\
\text { en crecimiento (erosivas) alineadas entre ellos. }\end{array}$ & $\begin{array}{l}\text { Depósitos eólicos de grano fino poco potentes, en } \\
\text { ocasiones con evidencia arqueológica. } \\
\text { Pedogénesis, con desarrollo de turba en algunos } \\
\text { sectores. }\end{array}$ \\
\hline $\begin{array}{l}\text { AFLORAMIENTOS } \\
\text { TERCIARIOS }\end{array}$ & $\begin{array}{l}\text { Morfogénesis. Depositación eólica que genera un } \\
\text { manto arenoso sobre los afloramientos terciarios. } \\
\text { Desarrollo de talud en el contacto con la planicie } \\
\text { supramareal. Ambos depósitos albergan evidencia } \\
\text { cultural. }\end{array}$ & $\begin{array}{l}\text { Pedogénesis, desarrollo de un molisol. } \\
\text { Reactivación de la erosión de la cubierta eólica } \\
\text { de los cerros en los últimos dos siglos dejando al } \\
\text { descubierto registro cultural. }\end{array}$ \\
\hline
\end{tabular}

otras condiciones hidrodinámicas y ambientales, imperantes hace unos 6.000 años, con presencia de sustratos duros mesolitorales sobre los que pudieron asentarse las colonias explotadas por los grupos humanos. Los depósitos marinos vinculados con estas condiciones se hallarían por debajo de las facies regresivas (cordones conchiles o cheniers) que ahora constituyen los sedimentos superficiales, y en las que estos moluscos están prácticamente ausentes. Aquella edad en el Holoceno medio marca asimismo el inicio de una morfogénesis activa, responsable de la cubierta eólica desarrollada sobre los afloramientos terciarios del sector, que continuó hasta el Holoceno tardío.

La amplia planicie intermareal que rodea los cerros ha tenido el atractivo de la recurrente presencia de cetáceos varados, cuyo aprovechamiento está documentado en las fuentes etnográficas (Borella 1998). Asimismo, entre los depósitos cordoniformes que se han ido sucediendo hacia el $\mathrm{E}$, se desarrollaron pequeños cuerpos de agua que seguramente han congregado elementos de la fauna local como guanacos y aves acuáticas, así como a sus predadores, incluyendo a los antiguos habitantes del área.

Un milenio atrás, aproximadamente, se inició sobre los cerros el desarrollo de un suelo. Este evento pedológico sugiere un cambio en las condiciones ambientales, pero no se vincula con evidencia arqueológica, por el momento, en este sector, aunque sí en otros sectores bajo estudio en el sur de la bahía, así como en Cabo Vírgenes (Borrero y Franco 2001; Favier Dubois 2001; Favier Dubois y Manzi 2002). Finalmente, una reactivación erosiva en parte causada por el impacto antrópico de los dos últimos siglos en el área, afectó el paisaje, generando hoyadas de deflación sobre los mantos eólicos. Esta dinámica ha sepultado en numerosas ocasiones este suelo, pero también ha descubierto perfiles y dejado expuesta evidencia arqueológica.

\section{CONCLUSIONES}

Las edades de los sucesivos cordones de tormenta que presenta esta costa progradante permitieron asignar una cronología a los espacios que fueron paulatinamente accesibles a la ocupación humana a partir del Holoceno medio. Pudieron establecerse así fajas de territorio acotadas por cordones de edad conocida que proveyeron límites temporales máximos al material arqueológico ubicado entre ellos. Este registro podría corresponder a la presencia humana en momentos muy cercanos a la depositación de los cordones, o bien a la dinámica cultural que se desarrolló en el sector con posterioridad, ya que al permanecer en superficie no permiten una asignación temporal precisa. Lo que interesa en principio es que no pueden ser anteriores.

Otro punto importante que deseamos destacar es que al determinar la antigüedad máxima de una geoforma o depósito, esa evidencia da un término post quem para los materiales en superficie, pero no autoriza a pensar que todo el material que se depositó estará expuesto. Como nuestro ejemplo de la llanura de cheniers trata de mostrar, la exposición del material depositado en los ambientes que estamos tratando depende de la historia de erosión. De manera que el término post quem en muchos casos se aplica para material susceptible de ser encontrado en estratigrafía, dentro de depósitos con edades máximas conocidas, y con la posibilidad de ser datado independientemente.

De esta forma, en conjunto con los resultados sobre los procesos de formación del registro arqueológico, es posible desarrollar un programa de muestreo distribucional en superficie, que contemple el estudio de las características tecnológicas de los materiales ya recuperados (Franco en prep.). Ello permitirá realizar con posterioridad una integración con los conjuntos obtenidos en estratigrafía. 
Los sectores cuya cronología se remonta a unos 6.000 años atrás poseen palimpsestos más complejos (6.000 años de potencial incorporación de artefactos), conforme pasa el tiempo hay más espacio y menos tiempo para promediar evidencias de ocupaciones humanas. Esto se aprecia, por ejemplo, al comparar las menores dificultades para separar los distintos componentes óseos ubicados en las lagunas próximas al Cerro de los Gatos -más cercanos al Océano- respecto a las del Cerro Las Bandurrias -más alejados.

En síntesis, este espacio comienza a ser habitable con posterioridad al Holoceno medio. La lente de valvas de Mytilus (Cerro Las Bandurrias) proporciona la edad más antigua para la ocupación humana costera en la región, bajo circunstancias en las que el mar rodeaba los afloramientos rocosos terciarios (hoy cerros bajos) restringiendo el espacio disponible. La progradación de la costa, con posterioridad, permitió el paulatino acceso a una extensa planicie supramareal, cuyo aprovechamiento por parte de los grupos cazadores-recolectores prehistóricos ha sido recurrente desde entonces.

Debido a este proceso de exposición, la llanura mareal se ha ido integrando dentro de los rangos de acción humana como teatro de operaciones de actividades terrestres. Se ha visto que hay evidencias de presencia humana en la isla desde antes del inicio de este proceso de exposición, y la apropiación de ese espacio está testimoniada tanto por materiales estratificados como en superficie, todos los cuales son susceptibles de una evaluación cronológica sobre la base de su localización en combinación con el examen de propiedades tafonómicas. La geoarqueología y la tafonomía, entonces, se combinan para generar una base por sobre la cual resultará posible avanzar hacia una comprensión de las estrategias con que se realiza dicha apropiación.

\section{AGRADECIMIENTOS}

Al Dr. Marcelo Ferrero por sus sugerencias y por obsequiar al primer autor una copia de su tesis doctoral inédita efectuada en la zona de estudio. Al Dr. Marcelo A. Zárate. A los colegas participantes de los trabajos de campo: Patricia Campán, Florencia Borella, Nora Franco, Fabiana Martín, Sebastián Muñoz, Juan Bautista Belardi, Victoria Horwitz, Flavia Carballo Marina, Lorena L'Heureux y Ramiro
Barberena. También agradecemos a aquellos que colaboraron brindando apoyo logístico en el terreno, Nino Segurado (Panamerican Energy), Julio Mandrini (Ea. San Martín), Domingo Palma, y al personal del Museo de Río Grande. Finalmente, a los evaluadores del trabajo por sus útiles sugerencias. Este trabajo fue subsidiado por los proyectos Magallania (PIDBID 0554), Magallania II (PIP 4954) y Arqueología distribucional en escala supra-regional (Agencia PICT 04-00807).

\section{BIBLIOGRAFÍA}

BORELLA, F. 1998. El carroñeo de cetáceos en Tierra del Fuego. En Arqueología de la Patagonia Meridional (Proyecto Magallania). Editor L. A. Borrero, pp. 97 110. Ediciones Búsqueda de Ayllu, Concepción del Uruguay.

BORELLA, F. 2004. Tafonomía regional y estudios ar queofaunísticos de cetáceos en Tierra del Fuego y Patagonia meridional, British Archaeological Reports (BAR), International Series 1257, Archaeopress, Oxford, 119 págs.

BORELLA, F. y A. S. MUÑOZ. 2001. Tafonomía de Pinnípedos en el extremo sur patagónico. Libro de Resúmenes del XIV Congreso Nacional de Arqueología Argentina, pp. 239-240, Rosario.

BORELLA, F. y A. S. MUÑOZ. 2005. Tafonomía de Pinnípedos en el extremo sur patagónico. Trabajo enviado a Intersecciones en Antropología, Olavarría.

BORRERO, L. A. 1979. Excavaciones en el alero "Cabeza de León”. Isla Grande de Tierra del Fuego. Relaciones (Nueva Serie) 13: 255-271.

BORRERO, L. A. 2001. Tafonomía regional en el istmo Bahía Inútil-Bahía San Sebastián (Tierra del Fuego). http:// www.naya.org.ar

BORRERO, L. A. 2003. Taphonomy of the Tres Arroyos 1 Rockshelter, Tierra del Fuego, Chile. Quaternary International 109-110: 87-93.

BORRERO, L. A. y M. CASIRAGHI. 1980. Excavaciones en el sitio Bloque Errático 1 (San Sebastián, Tierra del Fuego). Relaciones de la Soc. Arg. de Antropología (Nueva Serie) 14: 129-142.

BORRERO, L. A. y FRANCO, N. V. 2001. Arqueología de Cabo Vírgenes, Provincia de Santa Cruz. Actas del XIII Congreso Nacional de Arqueología Argentina, Córdoba.

CARRARA, I. S. 1952. Lobos marinos, pingüinos y guaneras de las costas del litoral marítimo e islas adyacentes de la República Argentina. Ministerio de Educación, Universidad Nacional de La Plata, Facultad de Ciencias Veterinarias, Cátedra de Higiene e Industrias, Publicación Especial.

CIRGEO (Centro de Investigaciones en Recursos Geológicos, CONICET) 1996. Estudio mineralógico de muestras de sedimento de sitios arqueológicos localizados en Ba. San Sebastián, Provincia de Tierra del Fuego. PREPCONICET, Buenos Aires, MS. 
CODIGNOTTO, J. O. 1979. Hojas Geológicas 63a Cullen, 64a bahía San Sebastián y 65b Río Grande. Servicio Geológico Nacional, MS.

CODIGNOTTO, J. O. 1983. Depósitos elevados y/o de acreción Pleistoceno-Holoceno en la costa Fueguino-Patagónica. Simposio Oscilaciones del nivel del mar durante el último hemiciclo deglacial en la Argentina, pp. 1226. Mar del Plata.

CODIGNOTTO, J. O. 1996. Cuaternario y Dinámica Costera. Geología y Recursos Naturales de la Plataforma Continental Argentina, editado por V.A. Ramos y M.A. Turic, XIII Congreso Geológico Argentino y III Congreso de Exploración de Hidrocarburos, Relatorio 2: 17-28.

CODIGNOTTO, J. O. y N. MALUMIÁN. 1981. Geología de la región al norte del paralelo $54^{\circ} \mathrm{S}$ de la Isla Grande de Tierra del Fuego. Revista de la Asociación Geológica Argentina, XXVI (1) : 44-88.

CODIGNOTTO, J. O.; R. R. KOKOT y S. C. MARCOMINI 1992. Neotectonism and sea level change in coastal zone of Argentina. Journal of Coastal Research 8(1): 125-133.

DINCAUZE, D. 2000. Environmental Archaeology. Principles and Practice. Cambridge University Press, Cambridge.

FAVIER DUBOIS, C. M. 1998. Dinámica sedimentaria y cambios ambientales en relación al registro arqueológico y tafonómico del Co. Cabeza de León. Anales del Instituto de la Patagonia, Serie Ciencias Humanas, 26: 137-152, Magallanes, Chile.

FAVIER DUBOIS, C. M. 2001. Análisis geoarqueológico de los procesos de formación del registro, cronología y paleoambientes en sitios arqueológicos de Fuego Patagonia. Tesis Doctoral, Universidad de Buenos Aires, 246 págs., MS.

FAVIER DUBOIS, C. M. y MANZI, L. 2002. Análisis geoarqueológico regional de un suelo del Holoceno tardío en Cabo Vírgenes-Punta Dungeness. Impacto antrópico reciente y distribución del registro cultural. Anales del Instituto de la Patagonia, Serie Ciencias Humanas, 30: 203-212, Magallanes, Chile.

FERRERO, M. 1996. La sedimentación intermareal en la bahía de San Sebastián, Tierra del Fuego, Argentina. Tesis doctoral, Universidad de Vigo, España, MS.

FRINK, D. S. 1995. Application of the Oxidizable Carbon Ratio Dating Procedure and Its Implications for Pedogenic Research. Pedological Perspectives in Archaeological Research. SSSA Special Publication 44.

GOODALL, R.N.P. 1989. The Lost Whales of Tierra del Fuego. Oceanus 32 (1): 89-95.

GUICHÓN, R.A., A. S. MUÑOZ y L. A. BORRERO, 2000. Datos para una Tafonomía de restos óseos humanos en Bahía San Sebastián, Tierra del Fuego. Relaciones de la Sociedad Argentina de Antropología 25: 297-313.

HORWITZ, V. D. 1995. Ocupaciones Prehistóricas en el sur de Bahía San Sebastián (Tierra del Fuego, Argentina). Arqueología 5: 105-136, Buenos Aires.

LAMING EMPERAIRE, A., D. LAVALLÉ y R. HUMBERT. 1972. Le Site de Marazzi en Terre de Feu. Objets et Mondes 12(2): 244-255.

LISTA, R. 1887. Viaje al País de los Onas. Establecimiento Tipográfico de Alberto Núñez, Buenos Aires.

MARTIN, F. M. y BORELLA, F. 1999. Tafonomía de Tierra del Fuego: reevaluación de la arqueología de Cabeza de León. En Soplando en el viento...Actas de las 3as Jornadas de Arqueología de la Patagonia, pp. 439450, San Carlos de Bariloche.

MARTIN, F. M., R. BARBERENA y R. A. GUICHÓN. 2004. Erosión y huesos humanos. El caso de la localidad Chorrillos, Tierra del Fuego. Magallania 32: 125-142.

MASSONE, M., 2004. Los cazadores después del hielo. Centro de Investigaciones Diego Barros Arana, Santiago de Chile.

MASSONE, M., D. JACKSON y A. PRIETO. 1993. Perspectiva arqueológica de los Selk'nam. Centro de Investigaciones Diego Barros Arana, Dirección de Bibliotecas, Archivos y Museos, Santiago, Chile.

MASSONE, M., A. PRIETO, D. JACKSON y M. ARROYO 1998. Los cazadores tempranos y el fuego: nuevos antecedentes del sitio Tres Arroyos 1. IV Jornadas de Arqueología de la Patagonia, Resúmenes de Ponencias: 22-23, Río Gallegos.

MC MANAMON, F. F. 1984. Discovering sites unseen. Advances in Archaeological Method and Theory 7:223-292.

MEGLIOLI, A. 1994. Glacial Stratigraphy of Central and Northern Tierra del Fuego, Argentina. En The termination of the Pleistocene. Sudamqua, pp. 9-21.

MORELLO, F., L. CONTRERAS y M. SAN ROMÁN. 1999. La localidad de Marazzi y el sitio Marazzi 1, una reevaluación. Anales del Instituto de la Patagonia, Serie Ciencias Humanas, 27: 183-197.

PISANO, E. 1977. Fitogeografía de Fuego-Patagonia chilena. I. Comunidades vegetales entre las latitudes $52^{\circ}$ y $56^{\circ}$ Sur. Anales del Instituto de la Patagonia 8: $121-250$

POPPER, J. A. 1887. Exploración de la Tierra del Fuego. Boletín del Instituto Geográfico Argentino 8: 74-115.

PORTER, S. C.; M. STUIVER y C. J. HEUSSER. 1984. Holocene sea level changes along the Strait of Magellan and Beagle Channel, Southernmost South America. Quaternary Research 22: 59-67.

RAEDEKE, L. D. 1978. Formas del terreno y depósitos cuaternarios, Tierra del Fuego Central, Chile. Revista Geológica de Chile 5: 3-31.

SALEMME, M. y G. BUJALESKY. 2001. Condiciones para el asentamiento humano litoral entre Cabo San Sebastián y Cabo Peñas (Tierra del Fuego) durante el Holoceno medio. En Desde el País de los Gigantes, Perspectivas arqueológicas en Patagonia II: 519-531, Río Gallegos.

STUIVER, M. y REIMER, P. J. 1993. Extended ${ }^{14} \mathrm{C}$ Data Base and Revised Calib $3.0{ }^{14} \mathrm{C}$ Age Calibration Program. Radiocarbon 35: 215-230.

VILAS, F. E.; ARCHE, A.; GONZÁLEZ BONORINO, G.; ISLA, F. I. y FERRERO, M. 1987a. Sedimentación intermareal en Bahía San Sebastián, Tierra del Fuego, Argentina. Acta Geológica Hispánica 21-22: 253-260.

VILAS, F. E., A. ARCHE, M. FERRERO, G. BUJALESKY, F. I. ISLA y G. GONZÁLEZ BONORINO, 1987b. Esquema evolutivo de la sedimentación reciente en la Bahía de San Sebastián, Tierra del Fuego, Argentina. Thalassas 5 (1): 33-36.

VILAS, F.; ARCHE, A.; FERRERO M.; e ISLA, F. I. 1999. Subantartic macrotidal flats, cheniers and beaches in San Sebastian Bay, Tierra del Fuego, Argentina. Marine Geology 160: 301-326. 